\title{
Shape memory polyurethane foams
}

\author{
S. M. Kang, S. J. Lee, B. K. Kim* \\ Department of Polymer Science and Engineering, Pusan National University, Busan 609-735, Korea
}

Received 22 April 2011; accepted in revised form 4 August 2011

\begin{abstract}
Molded flexible polyurethane (PU) foams have been synthesized from polypropylene glycol (PPG) with different molecular weights $\left(M_{\mathrm{w}}\right)$ and functionalities ( $f$ ), and 2,4/2,6-toluene diisocyanate (TDI-80) with water as blowing agent. It was found that the glassy state properties of the foam mainly depended on the urethane group content while the rubbery state properties on the crosslink density. That is, PPG of low MW and low $\mathrm{f}$ (more urethane groups) provided superior glass state modulus, strength, density, shape fixity and glass transition temperature $\left(T_{\mathrm{g}}\right)$, while that of high $M_{\mathrm{w}}$ and high $f$ (higher crosslink density) showed high rubbery modulus and shape recovery. Consequently shape fixity of low $M_{\mathrm{w}}$ PPG decreased from 85 to $72 \%$ while shape recovery increased from 52 to $63 \%$ as the content of high $M_{\mathrm{w}}$ PPG increased from 0 to $40 \%$.
\end{abstract}

Keywords: smart polymers, polyurethane foam, dynamic mechanical properties, shape memory properties, density

\section{Introduction}

Shape memory polymers (SMPs) respond to stimuli such as temperature, electricity, $\mathrm{pH}$, ionic strength and light [1-4], and have many advantages like low density, good shape recovery and easy processing [5-9]. Thermally actuated SMPs have found broad applications in actuators, smart textiles and coatings, sporting goods $[10,11]$ and in biomedical devices [12]. Recently, triple shape effect and two way shape memory behavior which are largely based on thermal triggering have also been suggested. [13-15]. Excellent reviews have also been published along with recent developments $[6,16$, 17].

Molded flexible polyurethane foams are used in a broad range of applications including transportation seating and trim parts, packaging, furniture, and novelty items. The greatest advantage is that the foam is molded into the desired intricate shape and the need for cutting is eliminated $[18,19]$. If high shape fixity and high shape recovery are endowed to such foam products, precision molding with high durability will be implemented.
Shape memory effects of polyurethane foam have also been reported with regard to the thermomechanical properties [20,21], laser-activated foam device [22], effect of shape holding conditions [23], and for biomedical application [24, 25] Most of these studies use commercially available polyurethane foams. Consequently, the basic structure-property relationships of the shape memory foam have not been reported perhaps except those by the present groups [26, 27].

In this work molded flexible polyurethane foams have been synthesized from polypropylene glycol (PPG) with various molecular weights $\left(M_{\mathrm{w}}\right)$ and functionalities $(f)$, and 2,4/2,6-toluene diisocyanate with water as blowing agent. The reactivity, mechanical and dynamic mechanical and shape memory properties of the foams were analyzed along with basic structure- property relationship of the foam.

\section{Experimental}

\subsection{Raw materials}

Two types of polypropylene glycol (PPG), viz. SR240 and GP-3000 (KPX, Korea) with different

\footnotetext{
${ }^{*}$ Corresponding author, e-mail: bkkim@pnu.edu (c) BME-PT
} 
molecular weights $\left(M_{\mathrm{w}}\right)$ and functionalities $(f)$ were used. SR-240 has the number average molecular weight (determined by gel permeation chromatography) of 240, and functionality of 2, while $f=3$ and number average $M_{\mathrm{w}}=3000$ for GP-3000. The Toluene diisocynate (TDI-80) was provided by Dow Chemical whereas TA-350 as a cell-opener by KPX Chemicals. The water used as chemical blowing agent was distilled in our laboratory. L-626 (silicon surfactant), A1 (bis(2-dimethylaminoethyl) ether, amine catalyst) and methylene chloride (MC, blowing catalysts) and T-9 (stannous octoate, organometallic gelling catalyst) were provided by Air Products (USA) and used as received.

\subsection{Preparation of polyurethane foam}

The flexible foams were synthesized by one-shot method. All raw materials were first put into a $500 \mathrm{ml}$ beaker and mixed for $20 \mathrm{~s}$ at $3000 \mathrm{rpm}$ using a dispersing turbine type impeller of $2.5 \mathrm{~cm}$ diameter at $25^{\circ} \mathrm{C}$ and $70 \%$ relative humidity. Then the mixtures were discharged to an open mold (200x $200 \times 200 \mathrm{~mm}$ ) and the foam cake was cured for $48 \mathrm{~h}$ at room temperature. The NCO index (isocyanate equivalents/polyol equivalents) was fixed at 1.00. We designed and synthesized six types of molded flexible polyurethane foams having various ratios of the two polyols giving different average $M_{\mathrm{w}}$ and $\mathrm{f}$ values. The basic formulations are given in Table 1.

\subsection{Characterizations}

Kinetics of the foam formation was followed by the physical change of the properties. The cream time corresponds to the start of bubble rise and hence color of the mixture becomes creamlike from milk due to the formation of foam bubbles. Rise time is the starting point of stable network formation by intensive formations of urethane and urea linkages and crosslinkings by allophanate and biuret reactions. The two characteristic times were measured by a digital stop watch.

The density of the foam was measured according to ASTM D 1622 with sample size of $30 \times 30 \times 30 \mathrm{~mm}$ (width $\times$ length $\times$ thickness), and an average of at least five measurements was taken to report. The cell structure of the foam was studied with a polarized optical microscope (POM) at a magnification of 120. For the measurement, central part of the foam was cryogenically fractured in liquid nitrogen. The total number of cells was countered to report the number average size of the cell. Dynamic mechanical properties of the foam were measured using a dynamic mechanical thermal analyzer (DMTA, Rheometrics MK-IV) in tension mode. Samples were heated from -100 to $150^{\circ} \mathrm{C}$ at $5^{\circ} \mathrm{C} / \mathrm{min}, 10 \mathrm{~Hz}$ and $2 \%$ strain.

Tensile properties of the foam were measured at room temperature with an universal testing machine (UTM, Lloyd, UK) at $2.00 \mathrm{~mm} / \mathrm{min}$ with the specimen dimension of $4 \times 25 \times 0.3 \mathrm{~mm}$ (width $\times$ length $\times$ thickness). To measure the compressive strength, samples were cut into dimensions of $50 \times 50 \times 50 \mathrm{~mm}$ (width $\times$ length $\times$ thickness) and placed between metal plates and compressed to $50 \%$ of the original thickness.

Shape memory properties were characterized using a temperature controlled universal testing machine. The sample was first heated to a loading temperature $\left(T_{\mathrm{g}}+20^{\circ} \mathrm{C}\right)$ at $4^{\circ} \mathrm{C} / \mathrm{min}$ before it was loaded to a maximum strain $\left(\varepsilon_{\mathrm{m}}\right)$ of $100 \%$, followed by cooling to $\left(T_{\mathrm{g}}-20^{\circ} \mathrm{C}\right)$ at a rate of $7^{\circ} \mathrm{C} / \mathrm{min}$ under constant strain. Then the sample was unloaded, giving a substantial amount of shrinkage $\left(\varepsilon_{\mathrm{u}}\right)$ depending on the molecular and shape parameters of the foam. Then the sample was reheated to the loading temperature $\left(T_{\mathrm{g}}+20^{\circ} \mathrm{C}\right)$ to recover the strain, leaving a substantial amount of permanent strain $\left(\varepsilon_{\mathrm{p}}\right)$. These

Table 1. Formulations to synthesize the polyurethane foams, $T_{\mathrm{g}}$, and $G_{\mathrm{n}}^{\circ}$ (unit: pphp)

\begin{tabular}{|c|c|c|c|c|c|c|c|c|c|c|c|}
\hline & SR-240 & GP-3000 & TA-350 & L-626 & Water & A1 & T9 & M.C & TDI-80 & $\begin{array}{c}\mathbf{T}_{\mathbf{g}} \\
{\left[{ }^{\circ} \mathbf{C}\right]}\end{array}$ & $\begin{array}{c}\left.\mathrm{G}^{\circ} \mathrm{n} \cdot \mathbf{1 0}^{6}\right) \\
{[\text { dyne/cm }}\end{array}$ \\
\hline S10 & 100 & - & \multirow{6}{*}{2} & \multirow{6}{*}{1} & \multirow{6}{*}{1.6} & \multirow{6}{*}{0.2} & \multirow{6}{*}{0.1} & \multirow{6}{*}{3} & 52.81 & 49.8 & 2.3 \\
\hline S08 & 80 & 20 & & & & & & & 47.06 & 39.6 & 3.6 \\
\hline S06 & 60 & 40 & & & & & & & 41.30 & 26.5 & 4.1 \\
\hline S04 & 40 & 60 & & & & & & & 35.64 & -12.3 & 4.1 \\
\hline S02 & 20 & 80 & & & & & & & 29.92 & -15.1 & 4.7 \\
\hline S00 & - & 100 & & & & & & & 24.21 & -49.2 & 5.1 \\
\hline
\end{tabular}

pphp: part per hundred polyol 
three steps complete one thermomechanical cycle [28]. Shape fixity and shape recovery are defined by Equations (1) and (2) respectively:

$\%$ shape fixity $=\frac{\varepsilon_{\mathrm{u}}}{\varepsilon_{\mathrm{m}}} \cdot 100$

$\%$ shape recovery $=\frac{\varepsilon_{\mathrm{r}}}{\varepsilon_{\mathrm{m}}} \cdot 100$

where $\varepsilon_{\mathrm{r}}=\varepsilon_{\mathrm{u}}-\varepsilon_{\mathrm{p}}$ is the recovered strain.

\section{Results and discussion}

\subsection{Reactivity and foam density}

Reactivity of the foaming reaction caused measuring the cream time and rise time. Table 2 shows that the two characteristic times monotonically increase with the increases of average molecular weight and functionality of the polyol mixture. This implies that both gelling and blowing reactions become slower. The reactivity decrease is primarily due to the decreased concentration of $\mathrm{OH}$ group which reacts with the isocyanate. This is seen from the decreased amount of the diisocyanate used in Table 1.

Typical POM morphologies of the foam are shown in Figure 1 and the details are summarized in Table 1 where the cell size increases from 0.3 (S10) to $0.45 \mathrm{~mm}$ (S04) with increasing molecular weight and functionality of the polyol. In accordance with the increased cell size, foam density decreases from about 59 (S10) to $52(\mathrm{~S} 04)\left[\mathrm{kg} / \mathrm{m}^{3}\right]$ (Figure 2). The smaller cell size with low $M_{\mathrm{w}}$ polyol is due to the fast gelling reaction over the foaming reaction.

Table 2. Reactivity and cell size

\begin{tabular}{|lr|c|c|c|c|}
\hline & & S10 & S08 & S06 & S04 \\
\hline Cream time & {$[\mathrm{s}]$} & 9 & 11 & 14 & 18 \\
\hline Rise time & {$[\mathrm{s}]$} & 189 & 200 & 219 & 235 \\
\hline Cell size & {$[\mathrm{mm}]$} & 0.30 & 0.36 & 0.37 & 0.45 \\
\hline
\end{tabular}

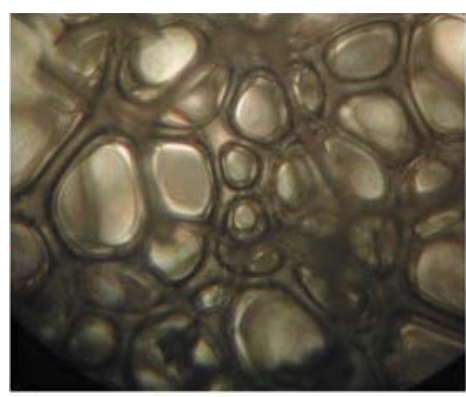

a)

Figure 1. Typical POM morphologies of the foams $(\times 120)$

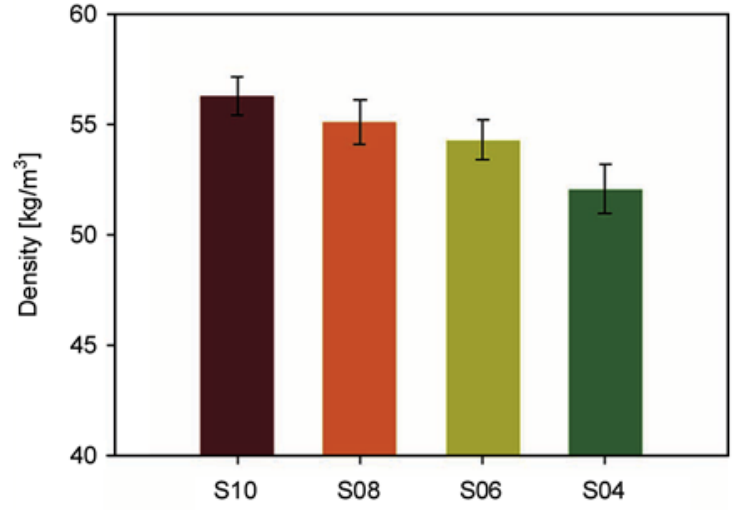

Figure 2. Density of the polyurethane foams

Then the cell becomes strong enough before it is blown keeping the cell small. Density is a most important parameter to control the mechanical properties of the foam. The decreased foam density is related to the decreased urethane group content and glass transition temperature of the foam to be discussed with the dynamic mechanical measurements to follow.

\subsection{Mechanical properties}

It is seen that the tensile stress-strain curves are almost linear regardless of polyol type (Figure 3).

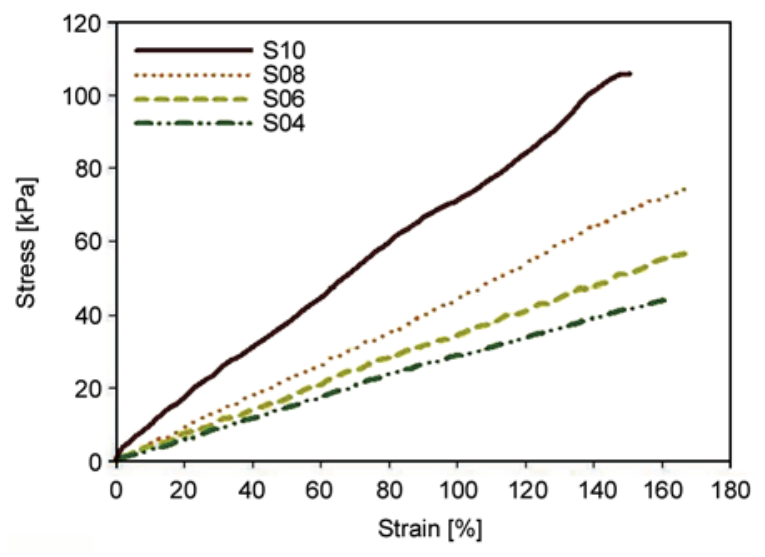

Figure 3. Tensile behaviors of the polyurethane foams

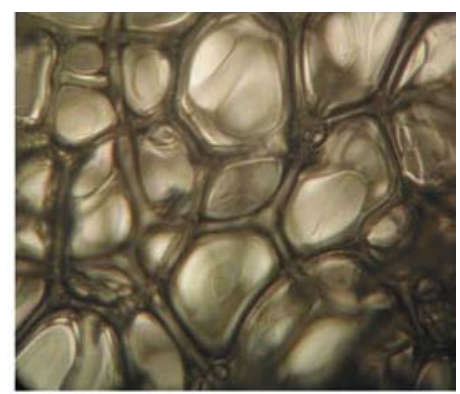

b) 


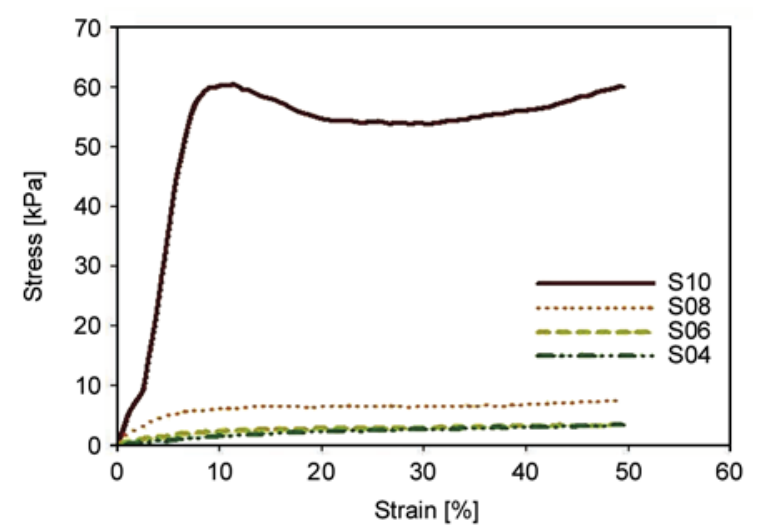

Figure 4. Compressive behaviors of the polyurethane foams

The initial modulus and break strength monotonically decrease with increasing molecular weight and functionality of the polyol while keeping the elongation at break almost constant. For example, the modulus of S10 is over 72 while that of S04 is about $25 \mathrm{kPa}$. The decrease is mainly due to the decreased $T_{\mathrm{g}}$ which on the other hand is introduced by the high molecular weight polyol which provides high chain flexibility and less urethane group. The two factors contribute to the lower $T_{\mathrm{g}}$ of the foam. It is mentioned that S02 and S00 showed insufficient loading capability to measure at room temperature. Figure 4 shows the compressive strength of the foam. The strength at $50 \%$ deformation of the original thickness was taken as the compressive strength of the foam. As expected the compressive modulus and strength decreases with increasing molecular weight and functionality of the polyol. Only S10 shows compression yield, necking-like behavior and strain hardening. It is noted that the compressive strength of S10 is greater than the tensile

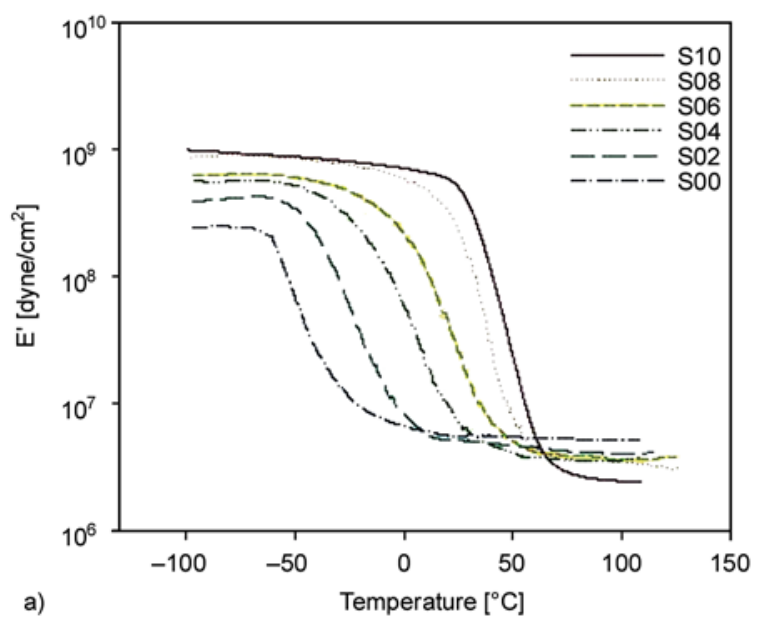

strength while those of others are lower than the tensile strength when compared at the same deformation (50\%). This is an indication that the $\mathrm{S} 10$ is in glassy state and others are in rubbery state.

\subsection{Dynamic mechanical properties}

The dynamic mechanical properties of the foams are given Figure 5 and Table 1 as a function of temperature. It is seen that the $T_{\mathrm{g}}$ of the foam which is seen in terms of tan $\delta$ peak decreases and the peak width broadens as the molecular weight and functionality of the polyol increases. The peak temperature ranges from about $-50^{\circ} \mathrm{C}(\mathrm{S} 00)$ to $50^{\circ} \mathrm{C}(\mathrm{S} 10)$. Since the broad peak is an indication of broad damping and heterogeneity of the sample, lower molecular weight polyol augments the homogeneity of PU by the increased more hydrogen bonding between the urethane groups.

It is of interest to note that the glassy state modulus decreases while the rubbery state modulus increases with increasing molecular weight and functionality of the polyol. The decreased glassy modulus is a direct response of the decreased density of the foam. Density should decrease with decreasing intermolecular force which in this case is the hydrogen bonding between the urethane groups. On the other hand, increasing rubbery modulus is due to the increased crosslink density of the foam. Crosslink is introduced mainly by the tri-functional polyol. It is also introduced by the biuret reactions between the free isocyanate and urea groups, as noted from the existence of the rubbery plateau for S10 having no trifunctional polyol. Urea groups are introduced by the foaming reaction between the free isocyanate and water.

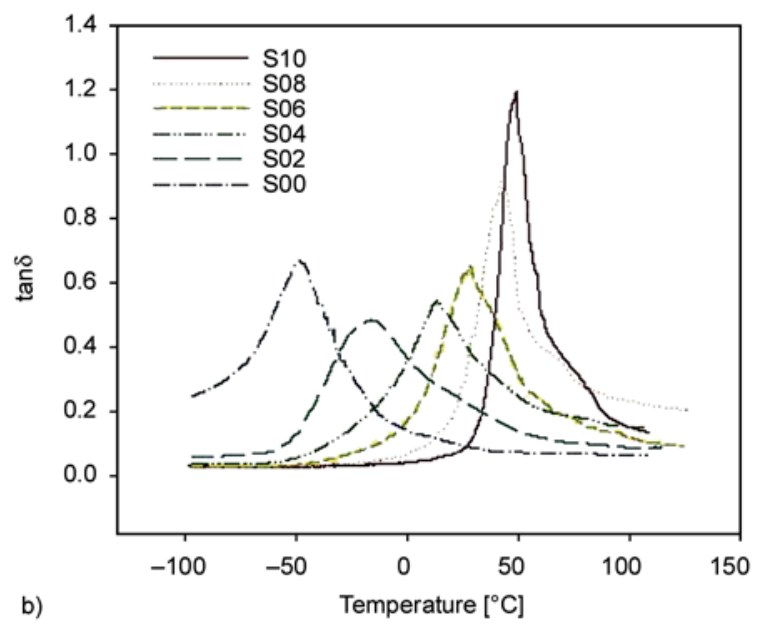

Figure 5. Dynamic mechanical properties of the polyurethane foams: storage modulus (a) and loss tangent (b) 
It is noted that rubbery plateau modulus increases as the functionality of the polyol increases in accordance with the ideal rubber theory as shon by Equation (3) [29]:

$G_{\mathrm{n}}^{\mathrm{o}}=\frac{\rho R T}{M_{\mathrm{c}}}$

where $\rho$ is the density, $R$ the gas constant, $T$ the absolute temperature and $M_{\mathrm{c}}$ the molecular weight between the crosslinks. This implies that crosslink introduced by the tri-functional polyol of high molecular weight governs the rubbery state modulus while in glassy state the secondary force mainly governs the physical and mechanical properties of the foam.

\subsection{Shape memory properties}

Figure 6 shows the cyclic loading and unloading behavior of the foam for the first four thermomechanical cycles. It is seen that the shape fixity decreases from about 84 (S10) to $72 \%$ (S06) while shape recovery increases from 52 (S10) to $63 \%$ (S06) with increasing molecular weight and functionality of the polyol [27]. This indicates that shape fixity depends on the glassy state modulus and shape recovery on the rubbery state modulus. This seems reasonable since shape is fixed during cooling where the slope of cooling step is the glass modulus [12] while the strain is recovered in rubbery state via the rubber elasticity which increases with increasing crosslink density. It is worth mentioning that the elastic strain energy viz. the area under the stress-strain curve is smaller with higher molecular weight polyol, thus the retractive force is maximum with S10. Regardless of polyol type, the cyclic hysteresis, viz. the reduction of area upon further cycling is mostly confined to the first cycle implying most chain breakages and chain slips are confined to the first cycle. However, it should be mentioned that the cyclic hysteresis of the foam is more serious than that of the elastomeric material $[5,28]$ due to the physical breakage of the cell structure, implying that foam is inherently more vulnerable to chain breakage upon tensile loading as compared with elastomeric materials.

\section{Conclusions}

The effects of molecular weight and functionality of polyol on the properties of molded flexible
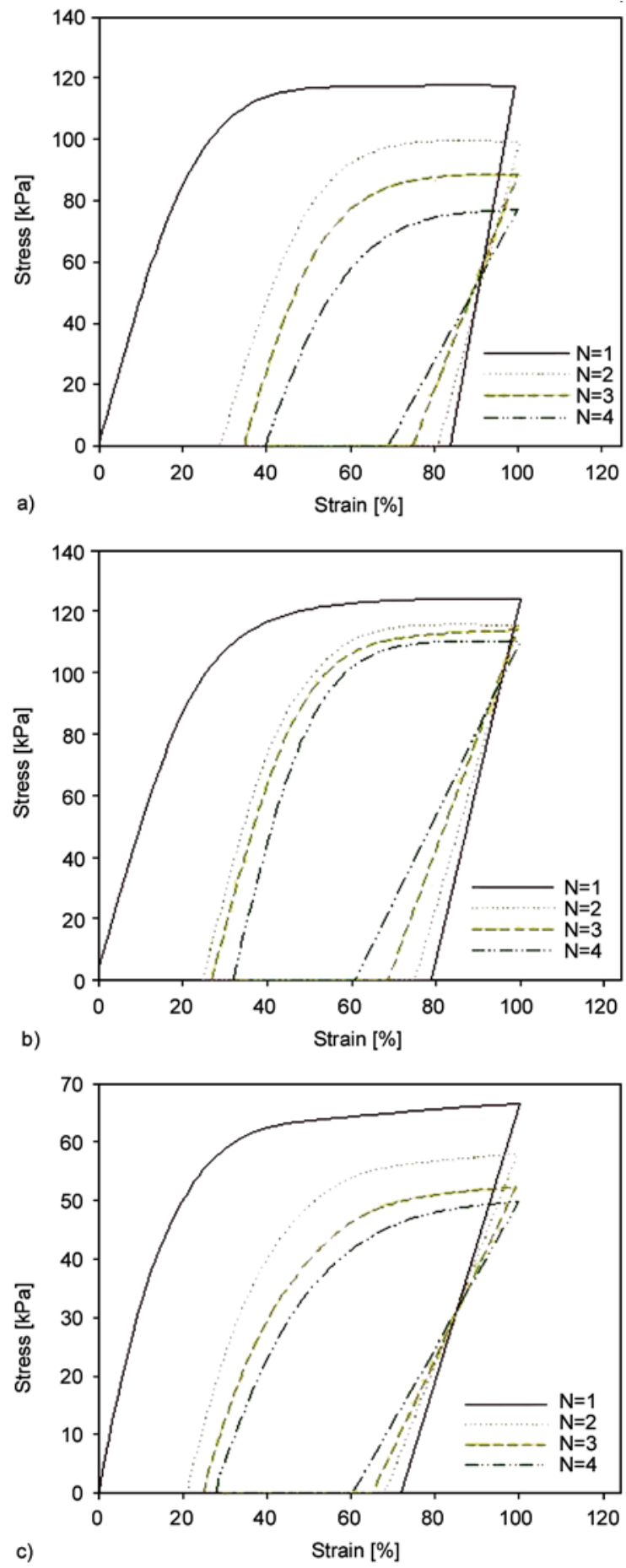

Figure 6. Thermomechanical cyclic behaviors of the polyurethane foams: (a) S10, (b) S08, (c) S06. $N$ is the number of cycle.

polyurethane foam were studied and the following conclusions were drawn.

The cream time and rise time monotonically increased with the increases of average molecular weight of the polyol mixture due to the decreased concentration of $\mathrm{OH}$ group. 
The glassy state properties of the foam mainly depended on the urethane group content, i.e., lower molecular weight polyol gave smaller cell size, higher foam density, strength and glass modulus. On the other hand, the rubbery state properties mainly depended on the crosslink density of the polyurethane, i.e., high crosslink density of high molecular weight of polyol gave high rubbery modulus according to the rubber elasticity. Consequently, high shape fixity of low molecular weight polyol is due to the high glassy state modulus while the high shape recovery of high molecular weight polyol due to the great rubber elasticity.

\section{Acknowledgements}

The research has been supported by the NCRC and PNUIFAM JRC both organized at PNU.

\section{References}

[1] Schmidt A. M.: Electromagnetic activation of shape memory polymer networks containing magnetic nanoparticles. Macromolecular Rapid Communications, 27, 1168-1172 (2006).

DOI: $10.1002 /$ marc. 200600225

[2] Lendlein A., Jiang H., Jünger O., Langer R.: Lightinduced shape-memory polymer. Nature, 434, 879882 (2005).

DOI: $10.1038 /$ nature 03496

[3] Scott T. F., Schneider A. D., Cook W. D., Bowman C. N.: Photoinduced plasticity in cross-linked polymers. Science, 308, 1615-1617 (2005). DOI: $10.1126 /$ science. 1110505

[4] Kolesov I. S., Radusch H-J.: Multiple shape-memory behavior and thermal-mechanical properties of peroxide cross-linked blends of linear and short-chain branched polyethylenes. Express Polymer Letters, 2, 461-473 (2008).

DOI: 10.3144/expresspolymlett.2008.56

[5] Lee B. S., Chun B. C., Chung Y-C., Sul K. I., Cho J. W.: Structure and thermomechanical properties of polyurethane block copolymers with shape memory effect. Macromolecules, 34, 6431-6437 (2001). DOI: $10.1021 / \mathrm{ma} 0018421$

[6] Lendlein A., Kelch S.: Shape-memory polymers. Angewandte Chemie International Edition, 41, 2034 2057 (2002).

DOI: $10.1002 / 1521-3773(20020617) 41: 12<2034::$ AIDANIE2034>3.0.CO;2-M

[7] Fan K., Huang W. M., Wang C. C., Ding Z., Zhao Y., Purnawali H., Liew K. C., Zheng L. X.: Water-responsive shape memory hybrid: Design concept and demonstration. Express Polymer Letters, 5, 409-416 (2011). DOI: $10.3144 /$ expresspolymlett.2011.40
[8] Huang W. M., Ding Z., Wang C. C., Wei J., Zhao Y., Purnawali H.: Shape memory materials. Materials Today, 13, 54-61 (2010). DOI: $10.1016 / \mathrm{S} 1369-7021(10) 70128-0$

[9] Sun L., Huang W. M.: Mechanisms of the multi-shape memory effect and temperature memory effect in shape memorypolymers. Soft Matter, 6, 4403-4406 (2010).

DOI: $10.1039 / \mathrm{COSM} 00236 \mathrm{D}$

[10] Zhu Y., Hu J., Yeung L-Y., Liu Y., Ji F., Yeung K-W.: Development of shape memory polyurethane fiber with complete shape recoverability. Smart Materials and Structures, 15, 1385-1394 (2006).

DOI: 10.1088/0964-1726/15/5/027

[11] D'hollander S., Van Assche G., Van Mele B., Du Prez F.: Novel synthetic strategy toward shape memory polyurethanes with a well-defined switching temperature. Polymer, 50, 4447-4454 (2009). DOI: $10.1016 /$ j.polymer.2009.07.021

[12] Smela E.: Conjugated polymer actuators for biomedical applications. Advanced Materials, 15, 481-494 (2003). DOI: $10.1002 /$ adma.200390113

[13] Kim B. K.: New frontiers of shape memory polymers. Express Polymer Letters, 4, 589 (2010). DOI: $10.3144 /$ expresspolymlett.2010.73

[14] Chung T., Romo-Uribe A., Mather P. T.: Two-way reversible shape memory in a semicrystalline network. Macromolecules, 41, 184-192 (2008). DOI: $10.1021 / \mathrm{ma} 071517 \mathrm{z}$

[15] Hong S. J., Yu W-R., Youk J. H.: Two-way shape memory behavior of shape memory polyurethanes with a bias load. Smart Materials and Structures, 19, 035022/1-035022/9 (2010). DOI: $10.1088 / 0964-1726 / 19 / 3 / 035022$

[16] Ratna D., Karger-Kocsis J.: Recent advances in shape memory polymers and composites: A review. Journal of Materials Science, 43, 254-269 (2008). DOI: $10.1007 / \mathrm{s} 10853-007-2176-7$

[17] Liu C., Qin H., Mather P. T.: Review of progress in shape-memory polymers. Journal of Materials Chemistry, 17, 1543-1558 (2007). DOI: $10.1039 / B 615954 \mathrm{~K}$

[18] Herrington R., Hock K.: Flexible polyurethane foams. Dow Chemical, Midland (1998).

[19] Neff R., Adedeji A., Macosko C. W., Ryan A. J.: Urea hard segment morphology in flexible polyurethane foam. Journal of Polymer Science Part B: Polymer Physics, 36, 573-581 (1997).

DOI: 10.1002/(SICI)1099-0488(199803)36:4<573:: AID-POLB4>3.0.CO;2-Q

[20] Tobushi H., Okumura K., Endo M., Hayashi S.: Thermomechanical properties of polyurethane-shape memory polymer foam. Journal of Intelligent Material Systems and Structures, 12, 283-287 (2001). DOI: 10.1106/FNSX-AP9V-QP1R-NMWV 
[21] Madbouly S. A., Lendlein A.: Shape-memory polymer composites. Advanced in Polymer Science. 226, 4195 (2010).

DOI: $10.1007 / 12200928$

[22] Maitland D. J., Small W., Rodriguez J., Wilson T. S., Ortega J. M., Buckley P. R., Hartman J.: Prototype laser-activated shape memory polymer foam device for embolic treatment of aneurysms. Journal of Biomedical Optics, 12, 030504/1-030504/3 (2007). DOI: $10.1117 / 1.2743983$

[23] Tobushi H., Matsui R., Hayashi S., Shimada D.: The influence of shape-holding conditions on shape recovery of polyurethane-shape memory polymer foams. Smart Materials and Structures, 13, 881-887 (2004). DOI: 10.1088/0964-1726/13/4/026

[24] Tey S. J., Huang W. M., Sokolowski W. M.: Influence of long-term storage in cold hibernation on strain recovery and recovery stress of polyurethane shape memory polymer foam. Smart Materials and Structures, 10, 321-325 (2001). DOI: $10.1088 / 0964-1726 / 10 / 2 / 318$
[25] Metcalfe A., Desfaits A-C., Salazkin I., Yahia L., Sokolowski W. M., Raymond J.: Cold hibernated elastic memory foams for endovascular interventions. Biomaterials, 24, 491-497 (2003).

DOI: 10.1016/S0142-9612(02)00362-9

[26] Lee S. H., Kim J. W., Kim B. K.: Shape memory polyurethanes having crosslinks in soft and hard segments. Smart Materials and Structures, 13, 1345-1350 (2004).

DOI: $10.1088 / 0964-1726 / 13 / 6 / 007$

[27] Lee S. H., Jang M. K., Kim B. K.: Shape memory effects of molded flexible polyurethane foam. Smart Materials and Structures, 16, 2486-2492 (2007).

DOI: 10.1088/0964-1726/16/6/052

[28] Kim B. K., Lee S. Y., Xu M.: Polyurethanes having shape memory effects. Polymer, 37, 5781-5793 (1996).

DOI: 10.1016/S0032-3861(96)00442-9

[29] Brydson J. A.: Rubbery materials and their compounds. Elsevier, London (1988). 